\title{
Effect of Microwave Power on the Physical Properties of Carboxylic Acid-Coated Manganese-Ion-Doped Zinc Sulfide Nanoparticles
}

\author{
Baibaswata Bhattacharjee ${ }^{1}$ and Chung-Hsin $\mathrm{Lu}^{2}$ \\ ${ }^{1}$ Department of Physics, Ramananda College, Bishnupur, Bankura, West Bengal 722 122, India \\ ${ }^{2}$ Department of Chemical Engineering, National Taiwan University, Taipei 10617, Taiwan
}

Correspondence should be addressed to Baibaswata Bhattacharjee, baib23@gmail.com

Received 23 March 2011; Accepted 18 April 2011

Academic Editor: John A. Capobianco

Copyright (C) 2011 B. Bhattacharjee and C.-H. Lu. This is an open access article distributed under the Creative Commons Attribution License, which permits unrestricted use, distribution, and reproduction in any medium, provided the original work is properly cited.

\begin{abstract}
Bright $\mathrm{ZnS}: \mathrm{Mn}^{2+}$ nanoparticles have been synthesized employing microwave irradiation technique and using zinc 2ethylhexanoate as a novel zinc precursor. A series of samples is obtained by changing the microwave power (from $150 \mathrm{~W}$ to $500 \mathrm{~W}$ ) to study its effect on the physical properties of the $\mathrm{ZnS}: \mathrm{Mn}^{2+}$ nanoparticles. The particle size increases with increasing microwave power for the samples synthesized in the microwave range of $150 \mathrm{~W}$ to $300 \mathrm{~W}$. The decrease in particle size for higher microwave power $(400 \mathrm{~W}$ and $500 \mathrm{~W})$ can be described as an onset of the secondary nucleation due to the excess energy associated with the higher microwave power. The sample synthesized with microwave power of $300 \mathrm{~W}$ shows highest luminescence intensity suggesting increase in $\mathrm{Mn}^{2+}$ luminescence center for the sample synthesized at $300 \mathrm{~W}$, as supported by the quantity analysis results.
\end{abstract}

\section{Introduction}

Over the last few years, a considerable interest in the novel optical and electrical properties of doped semiconductor nanocrystals has emerged [1-5]. Semiconductor nanocrystals are interesting from a physical and chemical point of view mainly because several of their properties are very different from those of bulk materials [3]. In particular, the significant size-dependent change in the band gaps has attracted much attention. This so-called quantum-size effect allows one to tune the absorption and emission colors of nanocrystal by varying the crystal radius.

$\mathrm{Mn}^{2+}$-doped materials represent a class of phosphors, which have already found their way in many applications. The ${ }^{4} \mathrm{~T}_{1} \rightarrow{ }^{6} \mathrm{~A}_{1}$ transition within the $3 \mathrm{~d}^{5}$ configuration of the divalent manganese ion has been studied extensively, and its orange-yellow luminescence in $\mathrm{ZnS}$ is well documented [6]. This luminescence has also been observed in nanocrystalline $\mathrm{ZnS}: \mathrm{Mn}^{2+}[7]$, and applications have already been suggested [8-10]. Different types of $\mathrm{Mn}^{2+}$ centers are present in nanocrystalline $\mathrm{ZnS}: \mathrm{Mn}^{2+}$, but the orange luminescence originates exclusively from $\mathrm{Mn}^{2+}$ ions on $\mathrm{Zn}^{2+}$ sites, where the $\mathrm{Mn}^{2+}$ is tetrahedrally coordinated by $\mathrm{S}^{2-}$. ZnS doped with manganese ions (yellow-orange emission at around $590 \mathrm{~nm}$ ) [7], copper ions (green emission at around $510 \mathrm{~nm}$ ) [11], and silver ions (blue emission at around $440 \mathrm{~nm}$ ) [12] have a potential application in field emission devices (FEDs) [13]. Organometallic methods for the synthesis of nanoparticles have been described by Bhargava et al. [7] and Gallagher et al. [14]. Yu et al. synthesized $\mathrm{ZnS}: \mathrm{Mn}^{2+}$ nanoparticles in methanol using sodium polyphosphate as the capping agent [15]. Recently, sonochemical synthesis [16] of $\mathrm{ZnS}: \mathrm{Mn}^{2+}$ nanoparticles has also been reported. Precipitations from homogeneous solutions have been reported where it was found that particle size is a function of the nature of the associated anions [17, 18]. Recently, the synthesis of in situ capping of carboxylic acid on $\mathrm{ZnS}: \mathrm{Mn}^{2+}$ nanoparticle surface resulting surface passivated bright nanophosphor has been reported employing microwave irradiation technique using zinc 2-ethylhexanoate as a novel zinc precursor [19].

This communication reports the systematic study on the effect of variation in synthesis condition, such as microwave 
power, and on the physical properties of the $\mathrm{ZnS}: \mathrm{Mn}^{2+}$ nanoparticles synthesized employing the similar technique used earlier [19].

\section{Experimental Details}

Microwave irradiation technique is employed to synthesize manganese-doped zinc sulfides $\left(\mathrm{ZnS}: \mathrm{Mn}^{2+}\right)$ nanoparticles. Zinc 2-ethylhexanoate $\left.\left[\mathrm{CH}_{3}\left(\mathrm{CH}_{2}\right)_{3} \mathrm{CH}\left(\mathrm{C}_{2} \mathrm{H}_{5}\right) \mathrm{COO}\right]_{2} \mathrm{Zn}\right]$ and thiourea $\left[\mathrm{NH}_{2} \mathrm{CSNH}_{2}\right]$ are dissolved at a molar ratio of $\mathrm{Zn} / \mathrm{S} 1$ to 10 in a solvent made by a mixture of methanol and deionized water (volume ratio 5:1). Excess amount of sulfur is used to ensure the completion of the reaction. Manganese acetate is used as the Mn precursor. 1 atomic \% $\mathrm{Mn}^{2+}$ doping was carried out through dissolving manganese acetate in the solution and stirred at room temperature for $15 \mathrm{~min}$. The solutions were then sonicated for $90 \mathrm{~min}$. A high-intensity ultrasonic bath (Branson 3510) is used for ultrasonic irradiation.

After sonication and 1 hour of stirring, the solution was transferred in a teflon autoclave upto $60 \%$ of its volume. The inner walls of the vessels are made of tetrafluormethaxil (TFM), and the outer walls are made of polyether ether ketone (PEEK). A high-performance microwave digestion unit (MLS $1200 \mathrm{Mega}$ ) operated at the frequency $2450 \mathrm{MHz}$ was used for microwave synthesis. The microwave generator was programmed to shut down for keeping the system at the set temperature. Once the reaction was over, the system was allowed to cool to room temperature. The microwave power was set at 150, 200,300,400, and $500 \mathrm{~W}$ to synthesize a series of $\mathrm{ZnS}: \mathrm{Mn}^{2+}$ nanoparticles. The precipitates were centrifuged, washed with deionized water, ethanol, and acetone for several times, and dried at $70^{\circ} \mathrm{C}$ in vacuum for characterization process.

Transmission electron microscopy (TEM) was performed using a Hitachi H-7100 microscope operated at the voltage of $100 \mathrm{kV}$. Powder dispersed in ethanol was carefully placed on the carbon-coated $\mathrm{Cu}$ grid for TEM study. X-ray diffraction (XRD) study was performed in an MAC M03 XHF diffractometer using $\mathrm{Ni}$-filtered $\mathrm{Cu} \mathrm{K}_{\alpha}$ radiation $(\lambda=$ $0.154056 \mathrm{~nm})$ as $\mathrm{X}$-ray source at $40 \mathrm{kV}, 30 \mathrm{~mA}$. The $\theta / 2 \theta$ scans were carried out at a scanning speed of $1^{\circ} / \mathrm{min}$ in the $2 \theta$ range of $20^{\circ}$ to $65^{\circ}$. Optical absorption spectra were recorded using a spectrophotometer (Hitachi-U3410) at the room temperature with a resolution of $\lambda \sim 0.07 \mathrm{~nm}$ along with a photometric accuracy of $\pm 0.3 \%$. The photoluminescence (PL) measurements were performed using a Hitachi F4500 fluorescence spectrophotometer using Xe lamp as an excitation source. Electron spin resonance (ESR) spectra were recorded using a Bruker EMX X-band spectrometer. The microwave frequency was $9.76 \mathrm{GHz}$, and a $100 \mathrm{kHz}$ field modulation was used. The quantity analysis of elements was performed using a inductively coupled plasma atomic emission spectrometer (ICP-AES, Kontron S-35).

\section{Results and Discussions}

3.1. Microstructural Study. Figure 1 shows the representative TEM of $\mathrm{ZnS}: \mathrm{Mn}^{2+}$ nanoparticles, synthesized at power of

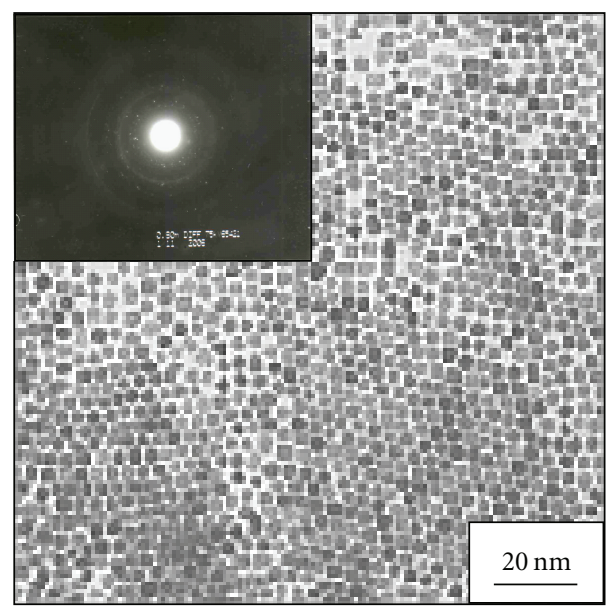

Figure 1: Transmission electron micrograph (TEM) with corresponding electron diffraction pattern with power condition at $300 \mathrm{~W}$.

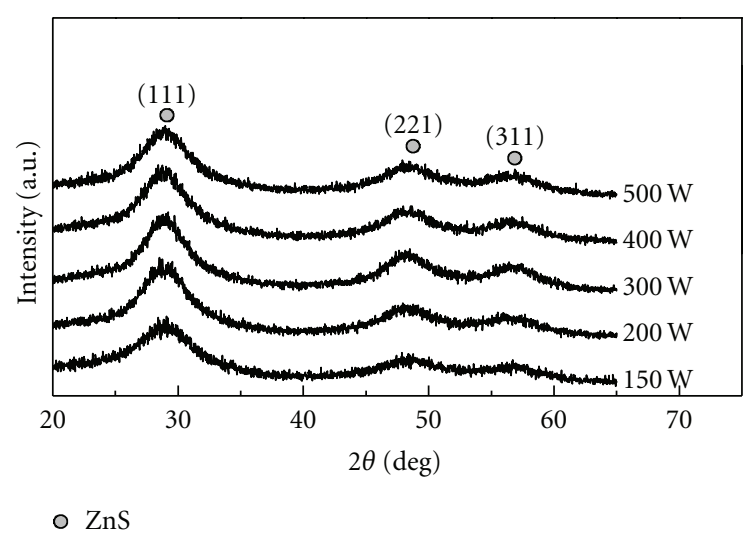

FIGURE 2: XRD pattern of 2-ethylhexanoic acid coated $\mathrm{ZnS}: \mathrm{Mn}^{2+}$ nanoparticles prepared using different microwave power.

$300 \mathrm{~W}$, with the corresponding diffraction pattern in inset. The presence of small, nearly monodisperse $\mathrm{ZnS}: \mathrm{Mn}^{2+}$ nanoparticles is clearly visible from the micrograph. The diffraction pattern of the sample consists of a central halo with concentric broad rings. The rings correspond to the reflections from (111), (220), and (311) planes confirming the cubic crystallographic structure of the $\mathrm{ZnS}$ nanoparticles. The average size $\left(D_{a v}\right)$ of the nanocrystallites determined from TEM is around $3.96 \mathrm{~nm}( \pm 0.5 \mathrm{~nm})$.

Figure 2 shows the wide-angle X-ray diffraction spectra of 1 atom \% Mn-doped $\mathrm{ZnS}$ nanoparticles in the $2 \theta$ range of $20-65^{\circ}$ synthesized using different microwave powers. All the samples exhibit very similar XRD patterns suggesting the same structure and nearly the same size for all the samples. The spectrum for the sample synthesized at $300 \mathrm{~W}$ showed sharpest peaks compared to the other samples indicating better crystalline nature of that sample. All samples showed reflections from (111), (220), and (311) plane confirming the zinc-blend structure. It is well known that the XRD pattern 
from the nanocrystal broadens due to the finite size effect, which is described in terms of the Scherrer formula

$$
L=\frac{0.9 \lambda}{\beta \cos \theta} \text {. }
$$

Here, the coherence length, $L$, is related to the full width at half-maximum (fwhm), $\beta$, of the peak centered at $\theta$, recorded with X-rays of wavelength, $\lambda$. The diameter, $d$, of the nanocrystal is then given by $d=(4 / 3) L$, assuming the particles are spherical in shape. The particle size obtained using (1) is shown in Table 1 for samples synthesized with different microwave power. It is interesting to note that the particle size increases for the samples synthesized using a microwave power from $150 \mathrm{~W}$ to $300 \mathrm{~W}$. When the microwave power reached $400 \mathrm{~W}$, the particle size becomes smaller. The same trend is observed for the nanoparticles synthesized using $500 \mathrm{~W}$ microwave power. The decrease in particle size for higher microwave power $(400 \mathrm{~W}$ and $500 \mathrm{~W}$ ) can be described as an onset of the secondary nucleation due to the excess energy associated with the higher microwave power. The microwave power can be described as a decisive factor for the microstructure and particle size of the samples synthesized using microwave irradiation. Excess energy associated with higher microwave power can "defocus" the particle nucleation process starting secondary nucleation, which shifts the average particle size to a lower value; even the starting solution has; same monomer concentration.

3.2. Optical Study. Figure 3 shows the optical absorption spectra of $\mathrm{ZnS}: \mathrm{Mn}^{2+}$ nanoparticles synthesized under different microwave powers. The UV-VIS absorption spectra show sharp absorption edges and sharp excitonic features characteristic of nearly monodispersed nanocrystals in every case. The sharp and asymmetrical peaks occurred in the range of wavelength around $291 \sim 304 \mathrm{~nm}$ for the samples prepared with varied microwave power. The sharp peaks are attributed to the electron-hole pairs caused by the quantum confinement, that is, an exciton energy level. The UV-absorption edge provides us a reliable estimate of the band gap of any system. The optical band gaps of these nanophosphors are obtained as $3.94 \mathrm{eV}$ for $500 \mathrm{~W}$, $3.86 \mathrm{eV}$ for $400 \mathrm{~W}, 3.82 \mathrm{eV}$ for $300 \mathrm{~W}, 3.91 \mathrm{eV}$ for $200 \mathrm{~W}$, and $4.00 \mathrm{eV}$ for $150 \mathrm{~W}$ microwave power, respectively, as shown in the inset of Figure 3. All the samples showed band gap value larger than that of bulk $\mathrm{ZnS}, 3.68 \mathrm{eV}$ [20], at room temperature suggesting quantum size effect in the samples due to their small sizes. To correlate the size of the nanocrystals with the band gap shift, one compares the calculated variation of band gap as a function of the size with the experimental values from the UV-VIS absorption spectra. Further, the blue shift of the band gap $\left(\Delta E_{g}\right)$ could also be utilized to determine the particle size using the relation [21]

$$
\begin{gathered}
\Delta E_{g}=E_{g(\text { nano })}-E_{g(\text { bulk })}=\left[\frac{h^{2} \pi^{2}}{2 \mu r^{2}}\right]-\left[\frac{1.8 e^{2}}{\varepsilon r}\right], \\
\mu=\left[\frac{1}{m_{e}^{*}}+\frac{1}{m_{h}^{*}}\right],
\end{gathered}
$$

TABle 1: Comparison of crystallite size calculated by Deby Scherrer equation and particle size calculated from optical analysis.

\begin{tabular}{lcc}
\hline $\begin{array}{l}\text { Microwave } \\
\text { power }(\mathrm{W})\end{array}$ & $\begin{array}{c}\text { Crystallite size }(\mathrm{nm}) \\
\text { from XRD pattern }\end{array}$ & $\begin{array}{c}\text { Particle size }(\mathrm{nm}) \\
\text { from optical analysis }\end{array}$ \\
\hline 150 & 3.13 & 3.57 \\
200 & 3.56 & 4.08 \\
300 & 3.96 & 4.44 \\
400 & 3.36 & 3.74 \\
500 & 2.71 & 3.29 \\
\hline
\end{tabular}

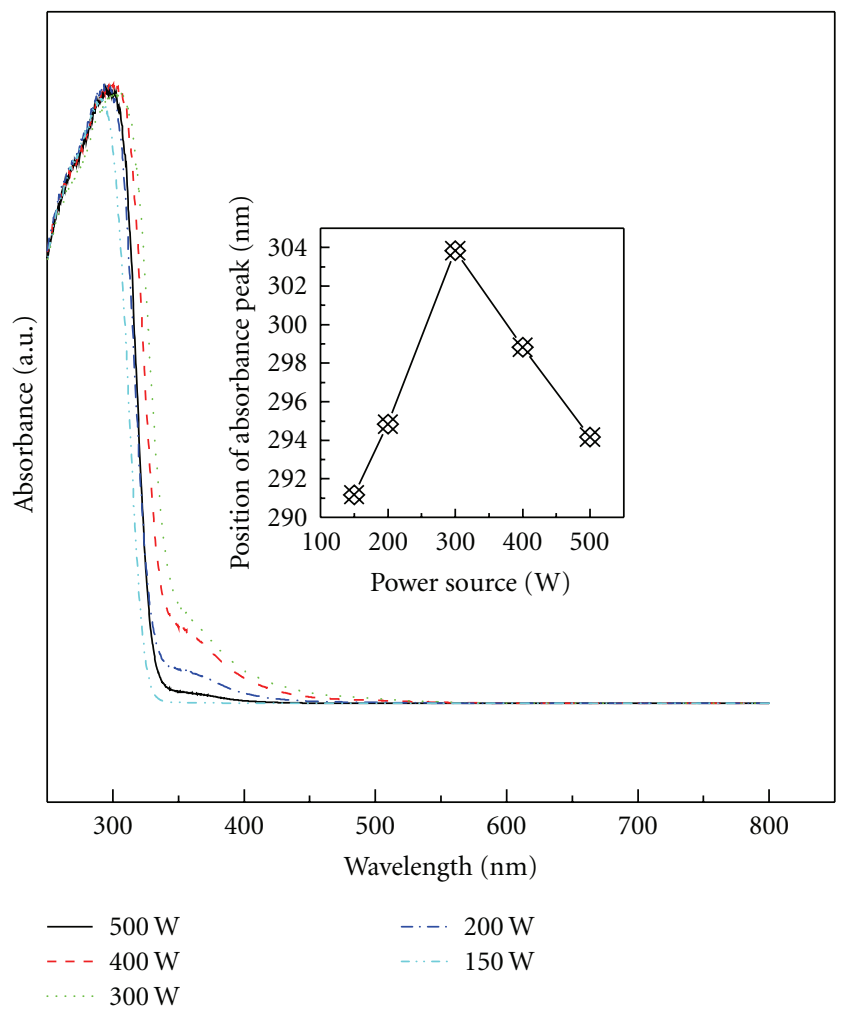

Figure 3: Optical absorption spectra of 2-ethylhexanoic acidcoated $\mathrm{ZnS}: \mathrm{Mn}^{2+}$ nanoparticles prepared using different microwave power. Inset shows variation of absorption peak positions for the samples synthesized using different microwave powers.

where $\varepsilon$ is the dielectric constant $(\varepsilon=8.76), h$ is Planck constant, $m_{e}^{*}$ and $m_{h}^{*}$ are the effective masses of electrons and holes $\left(m_{e}^{*}=0.34 m_{0}\right.$ and $\left.m_{h}^{*}=0.23 m_{0}\right)$, respectively, $e$ is the electronic charge, and $\mu$ is the reduced electron electronhole effective mass. To use the above equations, the particle sizes were determined as $3.29 \mathrm{~nm}$ for $500 \mathrm{~W}, 3.74 \mathrm{~nm}$ for $400 \mathrm{~W}, 4.44 \mathrm{~nm}$ for $300 \mathrm{~W}, 4.08 \mathrm{~nm}$ for $200 \mathrm{~W}$, and $3.57 \mathrm{~nm}$ for $150 \mathrm{~W}$, respectively. These values were comparable to those obtained from XRD studies, as shown in Table 1. The increase in the optical band gap and decrease in particle size for higher microwave power $(400 \mathrm{~W}$ and $500 \mathrm{~W})$ can be described as the onset of secondary nucleation due the application of excess microwave power as discussed in Section 3.1 
3.3. ESR Study. Room temperature ESR spectra of $\mathrm{ZnS}: \mathrm{Mn}^{2+}$ nanoparticles synthesized using different microwave powers measured at $9.76 \mathrm{GHz}$ are shown in Figure 4. All of these spectra are consistent with $\mathrm{Mn}^{2+}$ residing in the $\mathrm{Zn}^{2+}$ sites of the lattice. Hyperfine sextet due to the interactions between the d electrons and the spin-5/2 nucleus of the $\mathrm{Mn}$ is visible in the spectra. At low manganese-ion concentrations, a characteristic six line pattern of $\mathrm{Mn}^{2+}$ in the cubic $\mathrm{ZnS}$ lattice appears. In a cubic $\mathrm{ZnS}$ lattice containing substitutional $\mathrm{Mn}^{2+}$, hyperfine transitions are due to $\Delta M_{I}=0$, which gives rise to the characteristic six line spectrum. The spin Hamiltonian can be written as [22]

$$
\begin{aligned}
H= & g \beta \mathbf{H} \cdot \mathbf{S}+\frac{1}{6} a\left(S_{x}^{4}+S_{y}^{4}+S_{z}^{4}\right) \\
& +D\left[S_{z}^{2}-\frac{1}{3} S(S+1)\right]+A \mathbf{S} \cdot \mathbf{I} .
\end{aligned}
$$

Here, $\beta$ is the Bohr magneton, $\mathbf{H}$ is the applied magnetic field, and $g, D$, and $|A|$ are the ESR parameters. The first term in (4) is due to Zeeman interaction, the second is due to cubic field, the third is due to fine-structure splitting, and the fourth is due to hyperfine interaction with the Mn nucleus.

The sample synthesized at $150 \mathrm{~W}$ exhibits a distinct sixline spectrum having a larger hyperfine splitting with $\mathrm{g}$ and $|A|$ values 2.0013 and $89 \times 10^{-4} \mathrm{~cm}^{-1}$, respectively. Similar parameters were deduced by Kennedy et al. [22] for nanosized Mn-doped ZnS powder $(g=2.001$ and $|A|=$ $\left.89 \times 10^{-4} \mathrm{~cm}^{-1}\right)$. With increasing the microwave power, the values of both the ESR parameters decrease and reache at $g=$ 2.0009 and $88.8 \times 10^{-4} \mathrm{~cm}^{-1}$ for the sample synthesized at microwave power $300 \mathrm{~W}$. With the increase in microwave power, the spectra show less hyperfine splitting. The XRD and TEM studies indicate a growth of the particle sizes with increasing the microwave power up to $300 \mathrm{~W}$, so the change in the ESR structure can be attributed to the greater distance between the $\mathrm{Mn}^{2+}$ ions and the surfaces of the larger crystalline domains or particles. The broad background signals, superimposed to the hyperfine sextet, are likely due to magnetic interactions among the $\mathrm{Mn}^{2+}$ ions. It can be observed that these features become more prominent when the microwave power is changed from $150 \mathrm{~W}$ to $300 \mathrm{~W}$. As the particles coalesce, the axial fields decrease, but the $\mathrm{Mn}-\mathrm{Mn}$ interactions become stronger due to a decrease in the average separation between Mn ions. For the samples synthesized with microwave powers $400 \mathrm{~W}$ and $500 \mathrm{~W}$, EPR spectra again show more hyperfine splitting compared to the sample synthesized at $300 \mathrm{~W}$. This observation can be attributed to the smaller particle sizes in these samples, and the result is consistent with XRD and optical studies.

3.4. Photoluminescence (PL) Study. The room temperature PL spectra of the $\mathrm{ZnS}: \mathrm{Mn}^{2+}$ nanoparticles are presented in Figure 5. Each of the spectra consists of two emission bands. The main peak is the yellow-orange luminescence, a characteristic of the ${ }^{4} \mathrm{~T}_{1}$ (excited) $\rightarrow{ }^{6} \mathrm{~A}_{1}$ (ground) transition of $\mathrm{Mn}^{2+}$ ion at $T_{d}$ symmetry in $\mathrm{ZnS}$ host at about $590 \mathrm{~nm}$ [7]. A weak and broad blue emission centered at

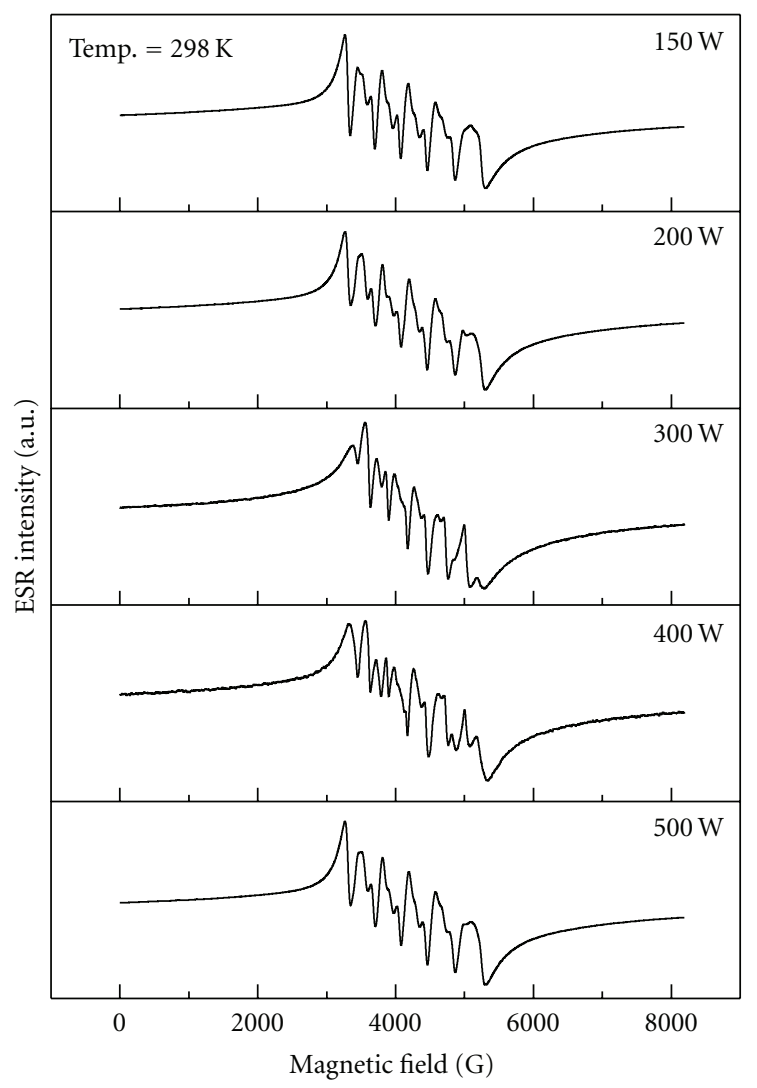

FIGURE 4: EPR spectra of 2-ethylhexanoic acid-coated $\mathrm{ZnS}: \mathrm{Mn}^{2+}$ nanoparticles prepared using different microwave power.

about $450 \mathrm{~nm}$ was also observed in addition to this bright yellow-orange emission (not shown in the figure). The weak peak at blue region can be attributed to the $\mathrm{S}^{2-}$ vacancies in the $\mathrm{ZnS}$ host $[23,24]$.

It was reported [25] that in $\mathrm{Mn}^{2+}$-activated $\mathrm{ZnS}$ nanocrystals in which the $\mathrm{Mn}^{2+}$ ions are distributed outside the $\mathrm{ZnS}$ nano-crystals, the PL emission is totally different from that of $\mathrm{Mn}^{2+}$-doped $\mathrm{ZnS}$ nano-crystals in which the $\mathrm{Mn}^{2+}$ is incorporated within the nano-crystals. When the $\mathrm{Mn}^{2+}$ is incorporated within the crystals, both the $435 \mathrm{~nm}$ blue emission of $\mathrm{ZnS}$ and the orange $\mathrm{Mn}^{2+}$ emission at $590 \mathrm{~nm}$ are observed. However, in the $\mathrm{Mn}^{2+}$-activated $\mathrm{ZnS}$ nano-crystals in which the $\mathrm{Mn}^{2+}$ ions are distributed outside the $\mathrm{ZnS}$ crystals, no orange emission at $590 \mathrm{~nm}$ is observed, a new peak at $350 \mathrm{~nm}$ appears, and the blue $435 \mathrm{~nm}$ emission in $\mathrm{ZnS}$ is considerably quenched and shifted to $390 \mathrm{~nm}$. The comparison of these observations with the results of the present study suggests that in this case, the $\mathrm{Mn}^{2+}$ ions are incorporated within the $\mathrm{ZnS}$ nanoparticles.

It can be noticed that the main peak in spectrum for the sample synthesized at $300 \mathrm{~W}$ is red shifted $(\sim 8 \mathrm{~nm})$ compared to the sample synthesized at $150 \mathrm{~W}$. The peak position of the yellow emission undergoes a red shift with increasing particle size up to about $4.5 \mathrm{~nm}$ (for the sample prepared at microwave power $300 \mathrm{~W}$ ). When the microwave power is increased to $400 \mathrm{~W}$, the particle size is decreased to $4.08 \mathrm{~nm}$, and the peak position again shifts to lower 


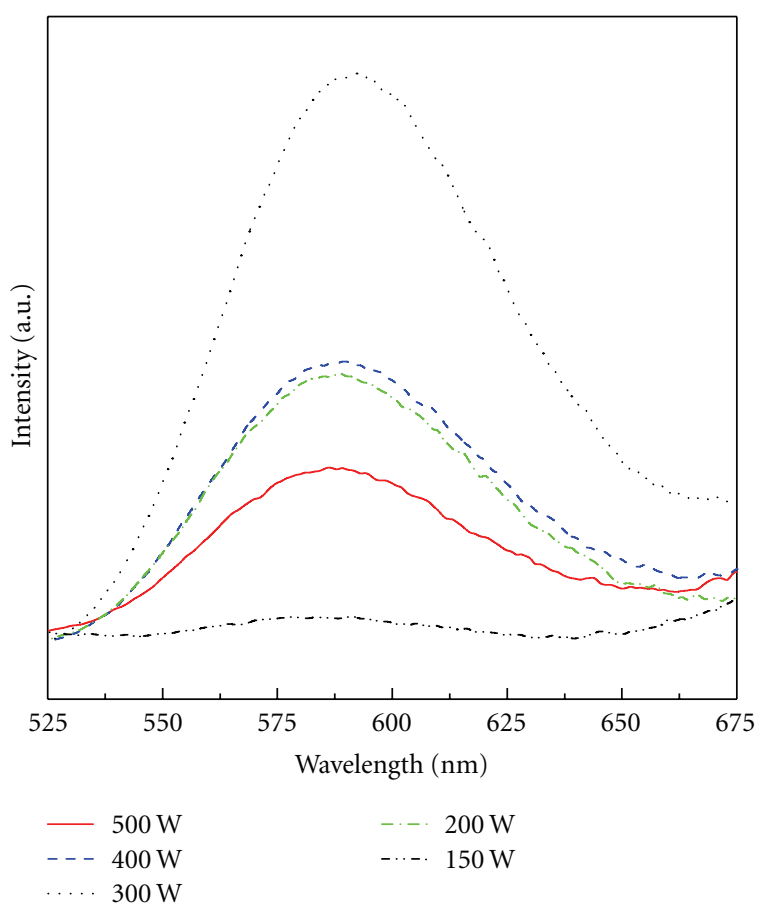

Figure 5: Photoluminescence emission spectra of 2-ethylhexanoic acid-coated $\mathrm{ZnS}: \mathrm{Mn}^{2+}$ nanoparticles prepared using different microwave power. The spectra are recorded under the excitation of $325 \mathrm{~nm}$ radiation.

wavelengths. The trend is continued for the sample prepared at $500 \mathrm{~W}$. The models involving either a size-dependent phonon coupling [26] and crystal fields [27] or a nearsurface location of the $\mathrm{Mn}^{2+}$ ions [28] can be presented as an explanation for the observed PL peak shift in the present study. It should be pointed out that the $\mathrm{Mn}^{2+}$ emission band in ZnS nanoparticles may shift to higher or to lower energies compared to bulk $\mathrm{ZnS}: \mathrm{Mn}^{2+}$, depending on both the size and the surface effects [26]. The increase in particle size leads to red shift of the emission peak consistent with quantum size effect. The decrease in the density of surface states with increasing particle size can be attributed to the observed red shift in emission peak wavelength. For the samples synthesized at $400 \mathrm{~W}$ and $500 \mathrm{~W}$ (Figure 5), the particle size decreases, which leads to the emission peak to the higher energy again.

The PL line shape is also found to change remarkably depending upon the microwave power used for synthesis. The sample obtained at the smallest microwave power (150 W) shows no significant yellow band exhibiting a broad blue emission. The yellow-orange emission peaked at about $590 \mathrm{~nm}$ is observed to get strengthened at the expense of the blue emission with increasing microwave power up to $300 \mathrm{~W}$ indicating a decreased disorder in the samples. Therefore, it may be suggested that the elevated local temperatures with increasing microwave power in the microwave-irradiated solution promotes improved crystallinity of the resulting product and also causes $\mathrm{Mn}^{2+}$ diffusion inside $\mathrm{ZnS}$ particles.

It is found that when the microwave power supply is set to $300 \mathrm{~W}$, the highest emission intensity is obtained.
This observation can be attributed to the increase in $\mathrm{Mn}^{2+}$ luminescence center for the sample synthesized at $300 \mathrm{~W}$, as supported by the ICP results shown in Table 2. It is found that the $\mathrm{Mn}^{2+}$ incorporation is highest $(\mathrm{Zn} / \mathrm{Mn}=1: 0.0039)$ in $\mathrm{ZnS}$ structure when the microwave power is set at $300 \mathrm{~W}$. $\mathrm{Mn}^{2+}$ incorporation in $\mathrm{Zn}^{2+}$ site decreases for both cases: if the microwave power is (a) increased beyond $300 \mathrm{~W}$ or (b) decreased below $300 \mathrm{~W}$. The decrease in luminescence intensities in the samples synthesized at microwave powers beyond or below $300 \mathrm{~W}$ can be associated with less number of luminescence centers present in those samples compared to the sample synthesized with $300 \mathrm{~W}$.

The luminescence quantum efficiency of the samples, synthesized at different levels of microwave powers, was calculated using the lamp phosphor $\mathrm{BaMgAl}_{10} \mathrm{O}_{17}: \mathrm{Eu}^{2+}$ (BAM, commercial phosphor purchased from Philips). This phosphor has a known quantum efficiency of about $90 \%$ for an excitation wavelength of $300 \mathrm{~nm}$ [12]. The emission spectra $\left(\lambda_{\text {exc }}=300 \mathrm{~nm}\right)$ of both BAM and the sample with unknown quantum efficiency were recorded under the same circumstances. To ensure the same packing density, the sample and the phosphor were weighed beforehand. The quantum efficiency was calculated with (5), assuming that BAM and the sample have about the same absorbance ( $\sim 100 \%$ according to diffuse reflection measurements) at an excitation wavelength of $300 \mathrm{~nm}$

$$
\mathrm{QE}_{\text {sample }}=\int I_{\text {sample }} \times \frac{\mathrm{QE}_{\mathrm{BAM}}}{\int I_{\mathrm{BAM}}},
$$

where $\mathrm{QE}_{\text {sample }}=$ quantum efficiency of the sample at $\lambda_{\mathrm{exc}}=$ $300 \mathrm{~nm}, \mathrm{QE}_{\mathrm{BAM}}=$ quantum efficiency of BAM at $\lambda_{\mathrm{exc}}=$ $300 \mathrm{~nm}(90 \%), \int I_{\text {sample }}=$ integrated emission intensity of the sample at $\lambda_{\mathrm{exc}}=300 \mathrm{~nm}$, and $\int I_{\mathrm{BAM}}=$ integrated emission intensity of BAM at $\lambda_{\mathrm{exc}}=300 \mathrm{~nm}$.

The quantum efficiency calculated with this formula gives a reasonable estimate of the actual quantum efficiency (error estimated to be about 10\%), and it provides a good way to compare the absolute quantum efficiencies of the various samples. The quantum efficiency of the sample synthesized at $300 \mathrm{~W}$ was found to be $15.3 \%$, which is the highest among the set of samples synthesized at other microwave power levels.

Therefore, it can be suggested from the experimental observations that there exists an optimum energy for synthesis of brightest $\mathrm{ZnS}: \mathrm{Mn}^{2+}$ nanoparticles corresponding to microwave power $300 \mathrm{~W}$. This condition of synthesis results in more complete crystal structure with fewer defects and also enhances the probability of manganese ions to substitute for zinc ions.

\section{Conclusions}

Highly luminescent $\mathrm{ZnS}: \mathrm{Mn}^{2+}$ nanoparticles are successfully synthesized employing microwave irradiation technique using zinc 2-ethylhexanoate as a novel zinc precursor. A series of $\mathrm{ZnS}: \mathrm{Mn}^{2+}$ nanoparticles is synthesized changing the microwave power (from $150 \mathrm{~W}-500 \mathrm{~W}$ ) when all other synthesis conditions are kept fixed. Electron spin resonance 
TABLE 2: Compositions of $\mathrm{ZnS}: \mathrm{Mn}^{2+}$ nanoparticles prepared at different power level measured by inductively coupled plasma atomic emission spectrometer.

\begin{tabular}{ccccc}
\hline Microwave power (W) & Zn (wt\%) & S (wt\%) & $\begin{array}{c}\text { Molar ratio } \\
\text { Zn/S/Mn }{ }^{2+}\end{array}$ \\
\hline 150 & 46.5 & 20.7 & 0.071 & $1.00: 0.91: 0.0018$ \\
200 & 45.6 & 21.2 & 0.099 & $1.00: 0.95: 0.0026$ \\
300 & 48.3 & 23.3 & 0.159 & $1.00: 0.98: 0.0039$ \\
400 & 49 & 24.4 & 0.097 & $1.00: 1.02: 0.0024$ \\
500 & 47.9 & 21.9 & 0.082 & $1.00: 0.93: 0.0020$ \\
\hline
\end{tabular}

(ESR) study showed a hyperfine sextet indicating wellseparated $\mathrm{Mn}^{2+}$ states without agglomeration for all the samples. All members of the series showed bright yelloworange luminescence at about $585 \mathrm{~nm}$, a characteristic of ${ }^{4} \mathrm{~T}_{1}$ (excited) $\rightarrow{ }^{6} \mathrm{~A}_{1}$ (ground) transition of $\mathrm{Mn}^{2+}$ ion at $T_{d}$ symmetry in $\mathrm{ZnS}$ crystals. The sample synthesized with microwave power of $300 \mathrm{~W}$ shows highest luminescence intensity.

\section{Acknowledgments}

The authors would like to thank DuPont Taiwan Ltd. and National Science Council, Taiwan, for the partial financial support of this study under Contract no. NSC100-3113E002-011.

\section{References}

[1] G. M. Liu, K. Wang, and Z. W. Zhou, "Influence of Doping on the Antibacterial Effect of $\mathrm{TiO}_{2}$ Nanoparticles," Eco-Materials Processing \& Design: Materials Science Forum, vol. 510-511, pp. 86-89, 2006.

[2] N. S. Norberg and D. R. Gamelin, "Giant Zeeman effects in colloidal diluted magnetic semiconductor quantum dots with homogeneous dopant speciation," Journal of Applied Physics, vol. 99, no. 8, pp. 104-106, 2006.

[3] A. P. Alivisatos, "Perspectives on the physical chemistry of semiconductor nanocrystals," Journal of Physical Chemistry, vol. 100, no. 31, pp. 13226-13239, 1996.

[4] J. Wang, J. Cai, Y.-H. Lin, and C.-W. Nan, "Room-temperature ferromagnetism observed in Fe-doped NiO," Applied Physics Letters, vol. 87, no. 20, Article ID 202501, 3 pages, 2005.

[5] K. Somaskandan, G. M. Tsoi, L. E. Wenger, and S. L. Brock, "Isovalent doping strategy for manganese introduction into III-V diluted magnetic semiconductor nanoparticles: InP:Mn," Chemistry of Materials, vol. 17, no. 5, pp. 1190-1198, 2005.

[6] D. R. Lide, Handbook of Chemistry and Physics, CRC Press, Boca Raton, Fla, USA, 74th edition, 1993.

[7] R. N. Bhargava, D. Gallagher, X. Hong, and A. Nurmikko, "Optical properties of manganese-doped nanocrystals of $\mathrm{ZnS}$," Physical Review Letters, vol. 72, no. 3, pp. 416-419, 1994.

[8] C. N. Xu, T. Watanabe, M. Akiyama, and X. G. Zheng, "Artificial skin to sense mechanical stress by visible light emission," Applied Physics Letters, vol. 74, no. 9, pp. 1236$1238,1999$.
[9] R. N. Bhargava, "Doped nanocrystalline materials-physics and applications," Journal of Luminescence, vol. 70, no. 1-6, pp. 85-94, 1996.

[10] J. F. Suyver, R. Bakker, A. Meijerink, and J. J. Kelly, "Photoelectrochemical characterization of nanocrystalline ZnS: Mn layers," Physica Status Solidi, vol. 224, no. 1, pp. 307-312, 2001.

[11] M. Wang, L. Sun, X. Fu, C. Liao, and C. Yan, "Synthesis and optical properties of $\mathrm{ZnS}: \mathrm{Cu}(\mathrm{II})$ nanoparticles," Solid State Communications, vol. 115, no. 9, pp. 493-496, 2000.

[12] T. Yamamoto, S. Kishimoto, and S. Iida, "Materials design for p-type $\mathrm{ZnS}$ with blue Ag emission by triple-codoping method," Physica Status Solidi, vol. 229, no. 1, pp. 371-375, 2002.

[13] S. C. Ghosh, C. Thanachayanont, and J. Dutta, "Studies on zinc sulphide nanoparticles for field emission devices," in Proceedings of the 1st ECTI Annual Conference (ECTI-CON '04), p. 145, 2004.

[14] D. Gallagher, W. E. Heady, J. M. Racz, and R. N. Bhargava, "Homogeneous precipitation of doped zinc sulfide nanocrystals for photonic applications," Journal of Materials Research, vol. 10, no. 4, pp. 870-876, 1995.

[15] I. Yu, T. Isobe, and M. Senna, "Optical properties and characteristics of $\mathrm{ZnS}$ nano-particles with homogeneous $\mathrm{Mn}$ distribution," Journal of Physics and Chemistry of Solids, vol. 57, no. 4, pp. 373-379, 1996.

[16] O. A. Korotchenkov, A. Cantarero, A. P. Shpak et al., "Doped ZnS:Mn nanoparticles obtained by sonochemical synthesis," Nanotechnology, vol. 16, no. 10, pp. 2033-2038, 2005.

[17] R. Vacassy, S. M. Scholz, J. Dutta, C. J. G. Plummer, R. Houriet, and H. Hofmann, "Synthesis of controlled spherical zinc sulfide particles by precipitation from homogeneous solutions," Journal of the American Ceramic Society, vol. 81, no. 10, pp. 2699-2705, 1998.

[18] S. M. Scholz, R. Vacassy, J. Dutta, H. Hofmann, and M. Akinc, "Mie scattering effects from monodispersed $\mathrm{ZnS}$ nanospheres," Journal of Applied Physics, vol. 83, no. 12, pp. 7860-7866, 1998.

[19] C. H. Lu, B. Bhattacharjee, and S. Y. Chen, "Microwave synthesis of manganese-ion-doped zinc sulfide nano-phosphors using a novel monomer," Journal of Alloys and Compounds, vol. 475, no. 1-2, pp. 116-121, 2009.

[20] Landolt-Bornstein, Numerical Data and Functional Relationships in Science and Technology, vol. 22a, Springer, New York, NY, USA, 1987.

[21] Y. Kayanuma, "Quantum-size effects of interacting electrons and holes in semiconductor microcrystals with spherical shape," Physical Review B, vol. 38, no. 14, pp. 9797-9805, 1988.

[22] T. A. Kennedy, E. R. Glaser, P. B. Klein, and R. N. Bhargava, "Symmetry and electronic structure of the Mn impurity in 
ZnS nanocrystals," Physical Review B, vol. 52, no. 20, pp. R14356-R14359, 1995.

[23] W. G. Becker and A. J. Bard, "Photoluminescence and photoinduced oxygen adsorption of colloidal zinc sulfide dispersions," Journal of Physical Chemistry, vol. 87, no. 24, pp. 48884893, 1983.

[24] A. A. Khosravi, M. Kundu, L. Jatwa et al., "Green luminescence from copper doped zinc sulphide quantum particles," Applied Physics Letters, vol. 67, p. 2702, 1995.

[25] K. Sooklal, B. S. Cullum, S. M. Angel, and C. J. Murphy, "Photophysical properties of ZnS nanoclusters with spatially localized Mn," Journal of Physical Chemistry, vol. 100, no. 11, pp. 4551-4555, 1996.

[26] W. Chen, R. Sammynaiken, Y. Huang et al., "Crystal field, phonon coupling and emission shift of $\mathrm{Mn}$ in $\mathrm{ZnS}: \mathrm{Mn}$ nanoparticles," Journal of Applied Physics, vol. 89, no. 2, pp. 1120-1129, 2001.

[27] H. Yang, P. H. Holloway, and B. B. Ratna, "Photoluminescent and electroluminescent properties of Mn-doped $\mathrm{ZnS}$ nanocrystals," Journal of Applied Physics, vol. 93, no. 1, pp. 586-592, 2003.

[28] A. G. Joly, W. Chen, J. Roark, and J. Z. Zhang, "Up-conversion luminescence of Mn2+ in ZnS:Mn2+ nanoparticles," Physical Review B, vol. 64, no. 4, Article ID 0412021, 4 pages, 2001. 

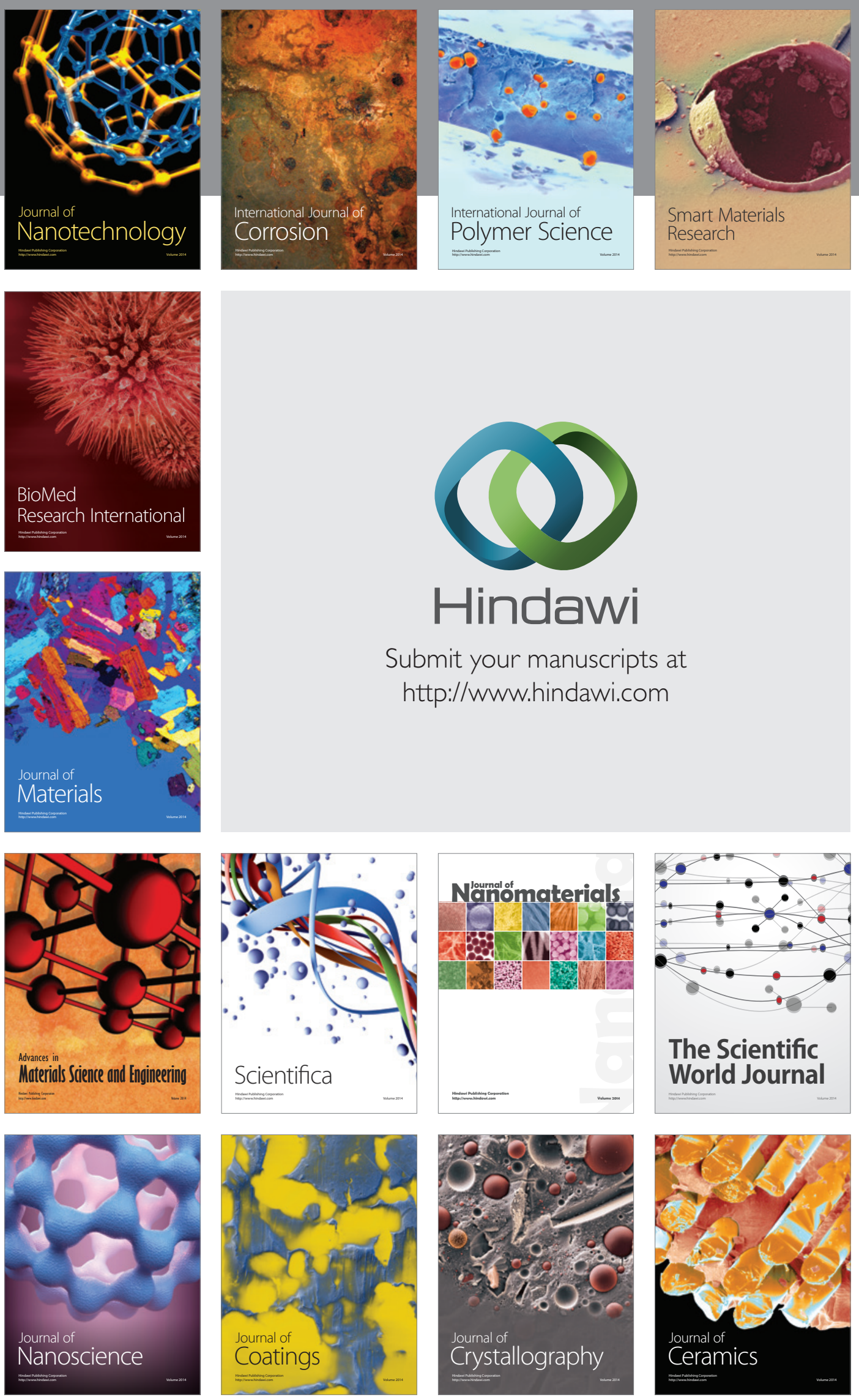

The Scientific World Journal

Submit your manuscripts at

http://www.hindawi.com

\section{World Journal}

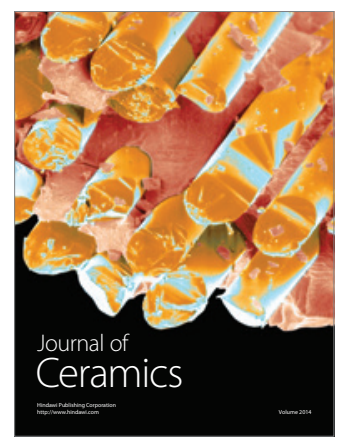

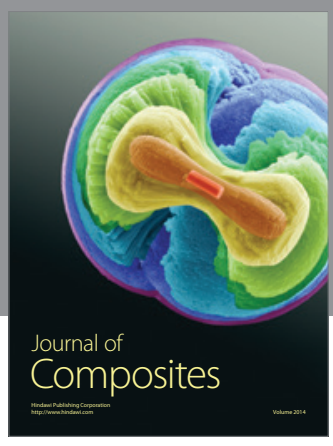
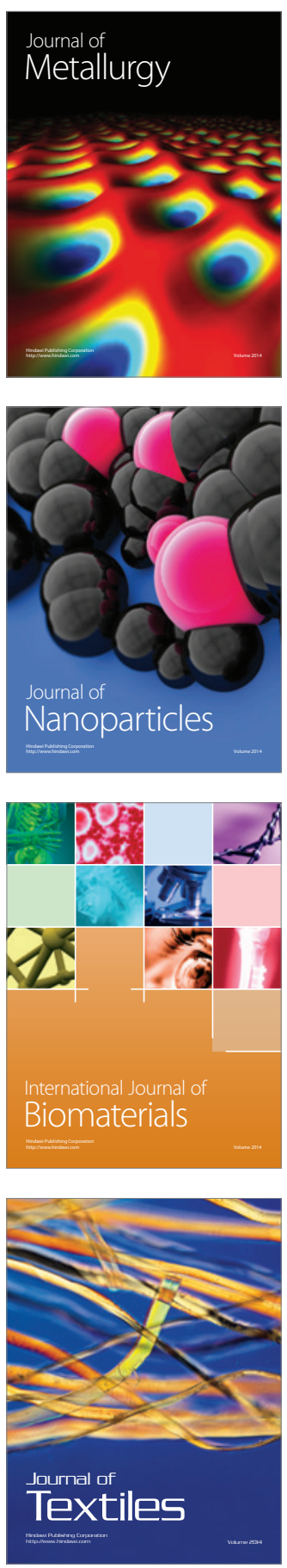